\title{
Basal ganglia calcification and psychosis in Down's syndrome
}

\author{
Michael E. Thase \\ M.D. \\ Western Psychiatric Institute and Clinic, Department of Psychiatry, University of Pittsburgh, Pittsburgh, P.A. \\ 15261, U.S.A.
}

\begin{abstract}
Summary
A case of basal ganglia calcification (diagnosed in vivo) and schizophreniform psychosis occurring in a young adult with Down's syndrome is reported. A stress-vulnerability model is suggested. Because of the relatively high prevalence of basal ganglia calcification in Down's syndrome, this population appears well suited for systematic study of the neuropsychiatric aspects associated with this neurological condition.
\end{abstract}

KEY WORD: schizophrenia.

\section{Introduction}

There is growing interest in the association between calcification of the basal ganglia and schizophreniform psychoses (Lowenthal and Bruyn, 1968; Francis, 1979). Systematic study of the relationship of these disorders has been limited by the rarity of basal ganglia calcification (BGC). Two recent surveys (Koller, Cochran, and Klawans, 1978; Murphy, 1979) demonstrated BGC in less than $0.5 \%$ of all computed tomographic (CT) scans reviewed. However, Malamud (1964) found BGC in 7\% of individuals with Down's syndrome (DS), suggestive that this population may be useful for prospective study of the behavioural correlates of BGC. While the clinical significance of BGC in DS is not known, a case was recently reported (Jakab, 1978) demonstrating the coexistence of idiopathic BGC and psychosis in an 18-year-old female with DS. In this paper, a second consecutive young adult with DS admitted to our hospital (cf. Jakab, 1978) with psychosis and BGC demonstrated by computed axial tomography is described.

\section{Case report}

A 32-year-old woman with moderate mental retardation (WAIS IQ:43) and trisomy G Down's syndrome was admitted for evaluation and treatment of a psychotic episode characterized by social withdrawal, paranoid ideation, and auditory hallucinations. She had been well at home and attending a daily activity programme until 6 months before admission, at which time she was allegedly raped by her sister's common-law husband. Shortly afterwards, she became progressively more withdrawn, ceased performing her household chores, stopped caring for herself, became incontinent of urine and stool, and would sit for hours staring into space. She began to speak out loud to herself in several distinctly different 'voices' and reported hearing commentary and derogatory auditory hallucinations. She became convinced that a man was watching her at all times and that this man planned to kill her. There was no previous personal or family history of neurological or psychiatric disorders.

On admission, she was an obese, short, lethargic woman with obvious features of DS. She appeared much older than her stated age and had faeces smeared over her abdomen. Her affect was anxious and she reported fearing that someone would harm her and to be hearing voices telling her that she was bad and going to die. She oriented to person and place, but not time, and could write her name. Physical examination was remarkable for perioral dermatitis, brachycephaly, epicanthal folds, Brushfield spots, gingivitis, protruding tongue, prominent abdomen, and short extremities.

Cardiovascular examination was unremarkable. Neurological evaluation revealed hyperactive deep tendon reflexes, bilateral ankle clonus, and bilateral palmomental reflexes. Posture was stooped and gait was slow and wide-based, with diminished arm swing. No tremor, cogwheeling, paresis, or dyskinetic movements were noted. Cranial nerve and sensory examinations were unremarkable.

Laboratory investigations included complete blood count, SMA-12 chemistry screen, calcium and phosphorus levels, and thyroid function studies (all within normal limits). Chest X-ray and electrocardiogram were unremarkable. Electroencephalogram (EEG) 
was mildly and diffusely abnormal with generalized slowing. Computer tomographic (CT) head scan demonstrated no evidence of cortical atrophy or ventricular dilatation; however, dense, bilateral basal ganglia calcification was found (Fig. 1).

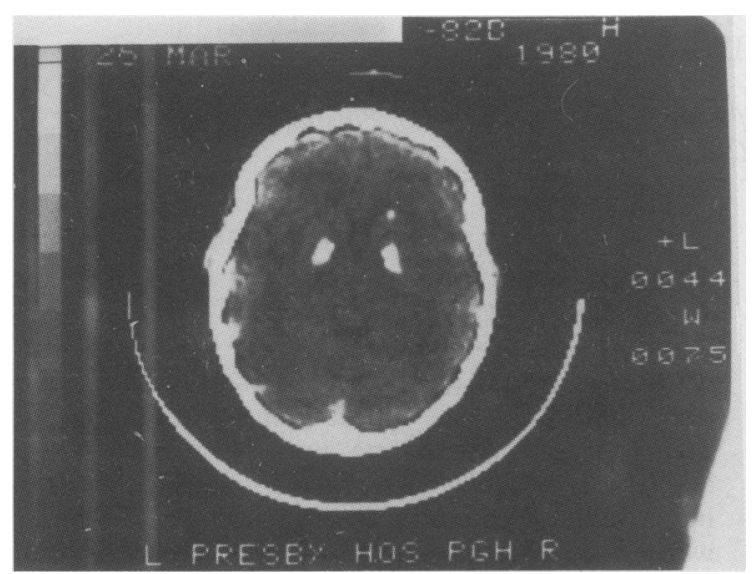

FIG. 1. Computerized axial tomogram of the brain showing dense, bilateral basal ganglia calcification.

Treatment was begun with thioridazine, $200 \mathrm{mg}$ at bedtime, and supportive, individualized activity therapy. The medication was tolerated without worsening of her mild extrapyramidal syndrome. During 2 weeks of inpatient treatment, her activity level and self-care improved, anxiety diminished, and she reported relief from her auditory hallucinations. She regained bowel and bladder continence. At time of discharge, she was alert, fully oriented, neatly dressed and groomed, and eager to return home. She was discharged under the care of her community mental health center and resumed her regular activities. Brief follow-up 6 months after discharged revealed no recurrence of psychosis.

\section{Discussion}

Basal ganglia calcification occurs in a wide range of clinical conditions, including hypoparathyroidism and pseudo-hypoparathyroidism (Babbitt et al., 1969), idiopathic familial degenerative diseases (Francis, 1979), and following cranial irradiation or intrathecal chemotherapy (Murphy, 1979). While rare in normal adults, the incidence of BGC increases with age, suggestive of age-related vascular changes (Murphy, 1979). Murofushi (1974) has postulated that the basal ganglia deposits in DS are due to cerebral circulatory insufficiency. Perhaps a critical factor in development of BGC is some impairment of the blood-brain barrier, whether from the toxic effects of irradiation or chemotherapy, ageing, microvasculature abnormality, or metabolic abnormality.
However, in the present case, there was no evidene of any underlying process aetiologically related to the development of BGC.

Psychotic episodes occur in about $10 \%$ of individ als with DS, roughly one half the rate expected in the moderately to profoundly mentally retarded popule tion overall (Gibson, 1978). However, such high rats of psychosis were determined in institutionalized samples and diagnoses were not based on explic $\mathbb{\$}$, operationalized criteria currently employed for clas)sification of schizophreniform disorders. When pret valence of psychosis is determined in communitybased samples of mentally retarded persons, ang diagnoses made according to DSM-III criteria, pre valence of psychosis may be proportionally lower (产. Eaton and Menolascino, 1982).

In Down's syndrome, psychosis is more likely occur in individuals with severe or profound mential retardation, presenile dementia, or seizure disordẹ, all conditions associated with more severe neur pathological abnormality (Gibson, 1978). In the present case, an early form of the presenile dementra associated with DS (Ellis, McCullough and Corley, 1974; Thase, 1982) was considered in the differentip] diagnosis because of the patient's deterioration, apathy, development of incontinence, encephalopathic EEG, and the presence of several released reflexes. While this diagnosis could not be ruled 8 ut the CT scan demonstrated no evidence of corkcts atrophy and the patient demonstrated considerabte symptomatic and social recovery with antipsychotic treatment.

In reporting the original case, Jakab (1978) did nळt suggest any causal connection between the presenoe of BGC and the development of psychosis. The occurrence of a second consecutive case with similar presentation and symptomatology is statistically unlikely and hence raises the index of suspicion aboug possible relationship. In both the present case and the case described by Jakab (1978), the behaviourgl decompensation shortly followed a severe sociul stressor, and therefore BGC may represent a vulner bility factor rather than a primary aetiology. Ait though the association may be fortuitous, it 8 interesting that the two conditions have similar prevalence in DS, at least in institutionalized samples [BGC:7\% (Malamud, 1964); psychosis: 10\% (Gibsod, 1978)]. To date, no studies have been published utilizing CT scanning in the assessment of a Do population, and thus a possible association cannot yet be examined either prospectively or retrospee tively. While further research is necessary to detefe mine if BGC represents a specific risk factor schizophreniform psychosis in DS, investigators terested in the neuropsychiatric manifestations of BGC should consider DS as a high risk population for systematic study. 


\section{Acknowledgment}

The author wishes to thank Irene Jakab, M.D., Ph.D. and Charles Reynolds III, M.D. for their helpful editorial suggestions and Ms Cathy Meres for her assistance in preparation of this manuscript.

\section{References}

BabBitT, D., TANG, T., DobBS, J. \& BERK, R. (1969) Idiopathic familial cerebrovascular ferrocalcinosis (Fahr's disease) and review of differential diagnosis of intracranial calcification in children. American Journal of Roentgenology, Radium Therapy, and Nuclear Medicine, 105, 352.

Eaton, L.F. \& Menolascino, F.J. (1982) Psychiatric disorders in the mentally retarded: Types, problems, and challenges. American Journal of Psychiatry, 139, 1297.

Ellis, W., MCCullogh, J. \& CoRley, C. (1974) Presenile dementia in Down's syndrome, ultrastructural identity with Alzheimer's disease. Neurology, 24, 104.

FrANCIS, A. (1979) Familial basal ganglia calcifications and schizophreniform psychosis. British Journal of Psychiatry, 135, 360.
GIBSON, D. (1978) Down's Syndrome: The Psychology of Mongolism, Cambridge University Press, Cambridge.

JAKAB, I. (1978) Basal ganglia calcifications and psychosis in mongolism. European Neurology, 7, 300.

Koller, W., Cochran, J. \& KLAWANS, H. (1978) Basal ganglia calcifications: computerized tomography and clinical correlations. Neurology, 28, 331.

Lowenthal, A. \& BRUYN, G. (1968) Calcification of the striopillidodentate system, In: Handbook of Clinical Neurology, Vol. 6 (Ed by P. Vinken \& G. Bruyn), p. 703. John Wiley, New York.

Malamud, N. (1964) Neuropathology. In: Mental Retardation (Ed by $H$. Stevens \& R. Herber), University of Chicago Press, Chicago.

MUROFUSHI, L. (1974) Symmetrischer pseudokalk in stammganglien und grosshirnmark mit diskreter leukencephalopathie bei Downschem syndrom. Neuropediatre, 5, 103.

MURPHY, M. (1979) Clinical correlations of CT scan-detected calcifications of the basal ganglia. Annals of Neurology, 6, 507.

THASE, M. (1982) Longevity and mortality in Down's syndrome. Journal of Mental Deficiency Research, 26, 177.

(Accepted 3 March 1983) 